\title{
Pengaruh Ikatan Diagonal GFRP Pada Hubungan Balok Kolom Pracetak Terhadap Kekuatan Sambungan
}

\author{
T. Hilmansyah ${ }^{\mathrm{a} *}$, H. Parung ${ }^{\mathrm{b}}$ dan R. Djamaluddin ${ }^{\mathrm{b}}$ \\ ${ }^{a}$ Jurusan Teknik Sipil, Fakultas Teknik Universitas Tadulako, Jl. Soekarno-Hatta Km 9, Palu 94118, Indonesia \\ ${ }^{b} J u r u s a n$ Teknik Sipil, Fakultas Teknik Universitas Hasanuddin, Jl. Perintis Kemerdekaan Km 10, Makassar 90245, Indonesia \\ ${ }^{*}$ Corresponding author's e-mail: teguhhilmansyah17@gmail.com
}

Received: 10 September 2020; revised: 15 February 2021; accepted: 15 February 2021

\begin{abstract}
Precast system is one of the reinforced concrete construction methods that can be used for development. GFRP-S (Glass Fiber Reinforced Polymer Sheet) is one of material that can be used as materials in precast concrete connections. The research aimed at analysing the strenght and behaviour of the concrete beams on beam-column joint precast with GFRP-S.The research was conducted at the Laboratory of Civil Engineering Structures and Materials Hasanuddin University. Beams dimensions was $15 \mathrm{~cm} \times 20 \mathrm{~cm} \times 120 \mathrm{~cm}$ and the column was $45 \mathrm{~cm} \times 20 \mathrm{~cm} \times 100 \mathrm{~cm}$. The testing materials were the precast beams with GFRP-S. The imposition given is monotonic static load in one direction.The results showed that an increase in stiffness of the precast beams with GFRP-S. LSI amounted to $16.64 \%$ of the LS. LIS amounted to $31.70 \%$ of the LS. The average deflection of LS are $55.05 \mathrm{~mm}$. The average deflection of LSI are $45.89 \mathrm{~mm}$. The average deflection of LIS are $37.60 \mathrm{~mm}$. The models of failure in the precast beams with GFRP-S are rupture failure of GFRP-S.
\end{abstract}

Keywords: GFRP-S, beam-column joint, rupture failure.

\begin{abstract}
Abstrak: Proses Sistem pracetak adalah salah satu metode konstruksi beton bertulang yang dapat digunakan untuk pembangunan. Glass fiber reinforced polymer sheet (GFRP-S) merupakan salah satu material yang dapat digunakan sebagai material pada sistem sambungan joint balok kolom pracetak. Penelitian ini bertujuan menganalisis kekuatan dan perilaku balok pada beton pracetak yang dilapisi GFRP-S. Penelitian dilakukan di Laboratorium Struktur dan Bahan Teknik Sipil Universitas Hasanuddin. Dimensi balok adalah $15 \mathrm{~cm} \times 20 \mathrm{~cm} x 120 \mathrm{~cm}$ dan kolom adalah $45 \mathrm{~cm} \times 20 \mathrm{~cm} \times 100 \mathrm{~cm}$. Benda uji adalah balok pracetak dengan GFRP-S. Pembebanan yang diberikan adalah beban statik monotonik satu arah.Hasil penelitian menunjukkan bahwa terjadi peningkatan kekakuan pada balok pracetak GFRP-S. LSI sebesar 16,64\% terhadap LS. LIS sebesar 31,70\% terhadap LS. Rata - rata lendutan LS sebesar 55,05 mm. Rata - rata lendutan LSI sebesar 45,89 mm. Rata - rata lendutan LIS sebesar 37,60 mm. Model kegagalan pada balok pracetak GFRP-S adalah rupture failure of GFRP-S.
\end{abstract}

Kata kunci: GFRP-S, joint balok-kolom, rupture failure.

\section{Pendahuluan}

Teknologi beton pracetak adalah suatu rancangan bangunan yang sifatnya cepat dan efisien dari segi pelaksanaannya. Salah satu bagian struktur yang sangat kritis adalah pertemuan balok - kolom (beam - column joint) [1-2]. GFRP (Glass Fiber Reinforced Polymer Sheet) adalah material yg menawarkan banyak keuntungan yaitu tahan terhadap korosi, kuat tarik yang besar dan ringan sehingga tidak memerlukan peralatan khusus untuk dapat membawanya kelokasi [3-5]. Berdasarkan hasil penelitian sebelumnya maka kami mencoba suatu metode pada joint balok - kolom dengan memberikan ikatan diagonal dengan maksud untuk mengurangi besarnya deformasi yang terjadi.

Joint balok-kolom dalam struktur statis tak tentu memegang peranan penting dalam pengengkangan agar tidak terjadi kebebasan rotasi pada balok [6-8]. Pengengkangan terjadi apabila joint balok-kolom merupakan satu kesatuan yang monolit dan kaku. Kekakuan joint diperlukan agar redistribusi unbalance moment pada analisis struktur dapat dilakukan. Struktur gedung harus memenuhi persyaratan "kolom kuat balok lemah", artinya ketika struktur gedung memikul pengaruh gempa rencana, sendi - sendi plastis di dalam struktur gedung tersebut hanya boleh terjadi pada ujung - ujung balok dan pada kaki kolom dan kaki dinding geser saja. Mengetahui secara tepat kuat lentur daerah sendi plastis balok, yang sengaja direncanakan sebagai bagian yang lemah merupakan hal yang sangat penting untuk memastikan kolom lebih kuat dari balok dan kegagalan getas akibat beban geser, tidak terjadi lebih awal dari terbentuknya sendi - sendi plastis [9].

Bangunan kadang difungsikan tidak sesuai dengan yang direncanakan sehingga beban yang bekerja pada struktur bangunan tersebut dapat melampaui dari yang diperhitungkan sebelumnya [10]. Untuk meningkatkan kemampuan struktur itu, maka kuat nominal penampang harus ditingkatkan dengan cara memperbesar dimensi atau dengan perkuatan eksternal. Khususnya untuk struktur beton, perkuatan eksternal yang paling sering dilakukan,karena sulitnya memperbesar dimensi [11-12]. Perkuatan dilakukan dengan menempelkan pelat dari material baja atau material lainnya kepermukaan elemen struktur. Salah satu material tersebut adalah Fiber Reinforced Polymer (FRP). FRP adalah material yang terbuat dari fiber (serat) material sintetis seperti glass, aramid atau carbon yang disatukan oleh zat matrik, seperti epoksi atau polyester [13-14]. Keuntungan dari penggunaan FRP adalah karena kemudahan pemasangannya, kuat tariknya yang tinggi, ringan, tahan korosi dan tidak menghantarkan listrik. Ada berbagai jenis FRP, tergantung 
pada fiber yang dipakai. Yang umum dikenal ada tiga, yaitu GFRP (Glass Fiber Reinforced Polymer), AFRP (Aramid Fiber Reinforced Polymer), dan CFRP (Carbon Fiber Reinforced Polymer).

Material GFRP yang sangat laku dipasaran adalah dalam bentuk lembaran, dimana keuntungan yang diperoleh dari GFRP-S tipe lembaran adalah kemudahan dalam aplikasi yaitu lembaran GFRP-S ini dapat ditempelkan dengan mudah pada bagian permukaan anggota struktur yang rusak dengan bantuan perekat (resin), biaya yang relatif murah dibandingkan FRP dengan bahan yang lain, kekuatan tarik yang tinggi, ketahanan yang tinggi terhadap kimia, memiliki sifat isolasi yang baik [15-16].

Disebut elemen balok-kolom apabila elemen dibebani lentur dan gaya tekan aksial. Perilaku balok-kolom tidak sama dengan perilaku balok maupun perilaku kolom. Beban aksial bekerja lebih kecil dibandingkan elemen kolom yang dipikul beban maksimum. Jadi terdapat sisa kapasitas untuk menahan momen lentur. Momen lentur pada elemen balokkolom terdiri dari momen primer yang diakibatkan oleh momen ujung dan momen sekunder akibat perkalian gaya aksial konstan dengan lendutan elemen, saat elemen inelastis, lendutan meningkat dan kapasitas momen lentur sebagian digunakan untuk menahan momen sekunder yang bekerja, sehingga elemen balok-kolom tidak dapat meningkatkan momen primernya [17-18]. Dengan kondisi ini diperkirakan daktalitas elemen balok-kolom yang dibebani aksial tekan dan momen lentur akan lebih kecil daripada daktilitas elemen balok yang hanya dibebani momen lentur dengan kondisi pembebanan sama. Apabila suatu beban menyebabkan timbulnya lentur, maka balok pasti akan mengalami defleksi atau lendutan. Meskipun sudah dicek aman terhadap lentur dan geser, suatu balok bisa tidak layak apabila terlalu fleksibel [19-20]. Dengan demikian tinjauan defleksi balok merupakan salah satu bagian dari proses desain (Spiegel dan linbrunner).

\section{Metode Penelitian}

Penelitian yang dilakukan adalah uji eksperimental dan kajian pustaka tentang pengujian kekuatan dan perilaku balok pada joint balok - kolom yang dilapisi dan dipasangi sabuk GFRP-S sebelum dan sesudah diberikan ikatan diagonal GFRP-S seperti pada Gambar 1.

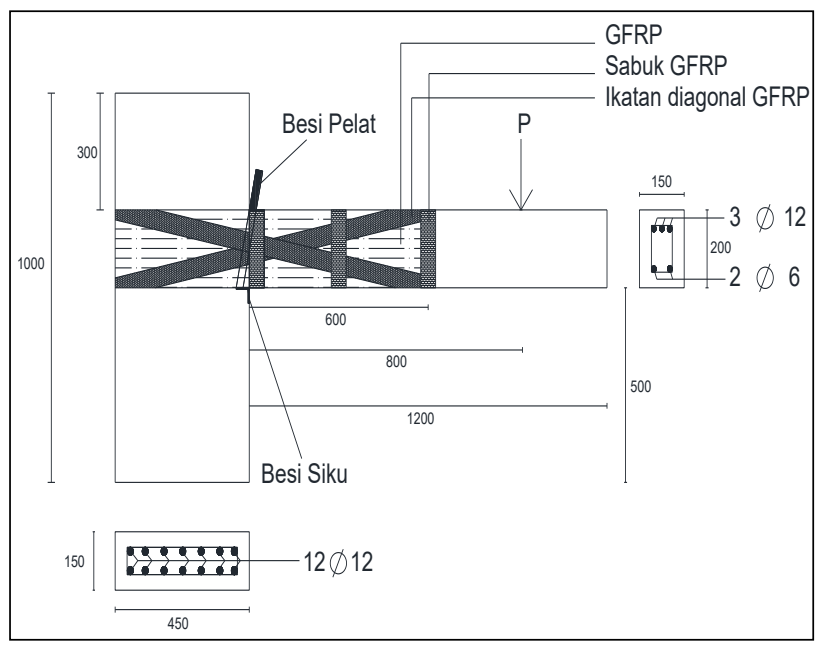

Gambar 1. Penempatan ikatan diagonal GFRP-S
Pengujian dilakukan diatas loading frame yang terbuat dari profil baja. Benda uji kemudian ditata sedemikian rupa, sehingga posisi dial, balok, kolom dan lokasi beban dipasang sesuai dengan bentuk pengujian (Gambar 2).

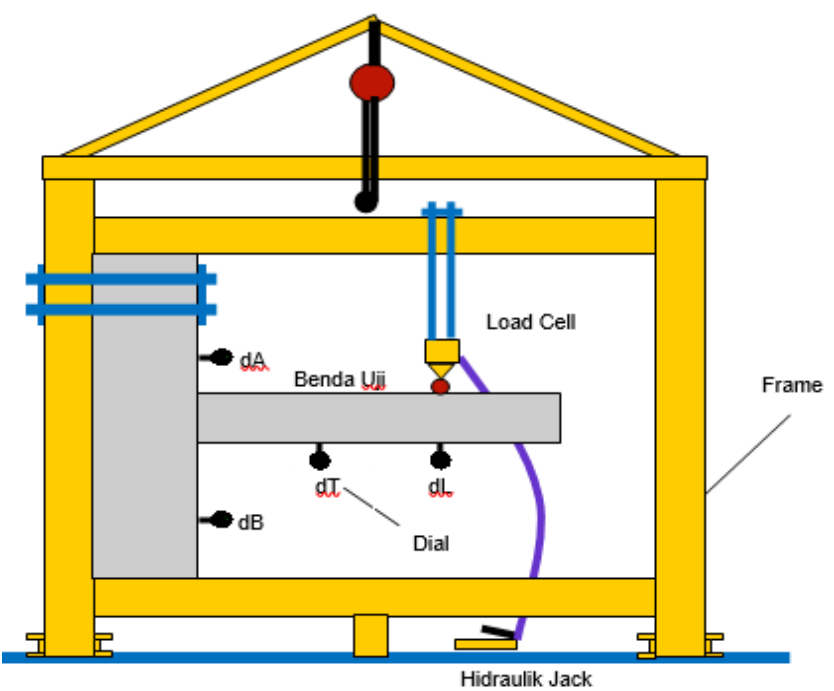

Gambar 2. Teknis pengujian

Dalam pembebanan joint balok - kolom eksterior dilakukan pembebanan monotonik 1 arah yaitu metode dengan pembebanan dari atas atau bawah saja. Dalam penelitian ini, hanya menggunakan pembebanan dari atas (Gambar 3).

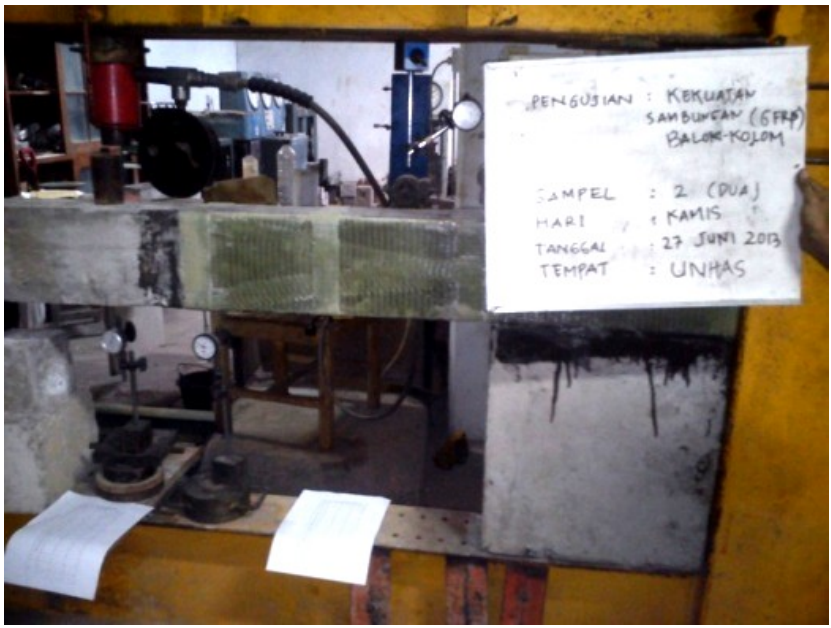

Gambar 3. Pembebanan monotonik 1 arah

\section{Hasil dan Pembahasan}

Pada Tabel 1 menunjukkan bahwa perbedaan lendutan antara beton pracetak tipe LS, tipe LSI dan tipe LIS pada saat beban maksimum cukup besar. Hal ini menunjukkan bahwa ikatan diagonal cukup berpengaruh terhadap kekakuan sambungan. Pada beton pracetak tipe LIS memiliki lendutan yang cenderung lebih kecil walaupun menerima beban yang relatif sama. Hal ini disebabkan pada ikatan diagonal juga dipasangi sabuk, sedangkan untuk tipe LSI dipasangi ikatan diagonal setelah balok dipasangi sabuk yang menunjukkan bahwa metode pemasangan ikatan diagonal tipe LIS lebih efektif dikarenakan ikatan diagonal 
REKONSTRUKSI TADULAKO: Civil Engineering Journal on Research and Development, Vol. 2(1), March 2021

dimanfaatkan lebih maksimal untuk meningkatkan kekakuan pada sambungan.

Tabel 1. Hubungan beban dan lendutan

\begin{tabular}{|c|c|c|c|c|c|}
\hline No. & $\begin{array}{c}\text { Kode } \\
\text { Beton }\end{array}$ & $\begin{array}{c}\text { Pcrack } \\
(k N)\end{array}$ & $\begin{array}{c}\begin{array}{c}\text { Lendutan } \\
(\mathrm{mm})\end{array} \\
\end{array}$ & $\begin{array}{c}\text { Pultimit } \\
(\mathrm{kN})\end{array}$ & $\begin{array}{c}\text { Lendutan } \\
(\mathrm{mm})\end{array}$ \\
\hline 1 & $\begin{array}{l}\text { Tipe } \\
\text { LS }\end{array}$ & 6,39 & 1,97 & 29 & 55,05 \\
\hline 2 & $\begin{array}{l}\text { Tipe } \\
\text { LSI }\end{array}$ & 7 & 3,81 & 29 & 45,89 \\
\hline 3 & $\begin{array}{l}\text { Tipe } \\
\text { LIS }\end{array}$ & 7 & 4,44 & 30 & 37,60 \\
\hline
\end{tabular}

Gambar 4 yang menyajikan hubungan beban dan lendutan untuk seluruh sampel menunjukkan bahwa penambahan ikatan diagonal tidak signifikan untuk meningkatkan kapasitas beban ultimit pada beton pracetak namun dapat mengurangi lendutan maksimum yang terjadi. Pada beton pracetak yang ditambahakan ikatan diagonal GFRP-S nampak bahwa tipe LIS lebih dapat menambah kekakuan pada joint balok-kolom daripada beton pracetak tipe LSI. Hal ini ditunjukkan dengan lendutan maksimum untuk beton pracetak tipe LIS lebih kecil daripada beton pracetak tipe LSI. Dengan demikian dapat dikatakan bahwa semakin tebal lapisan GFRP-S yang ditambahkan dengan ikatan diagonal maka kekakuan sambungan juga semakin besar namun sifat dari balok akan semakin getas.

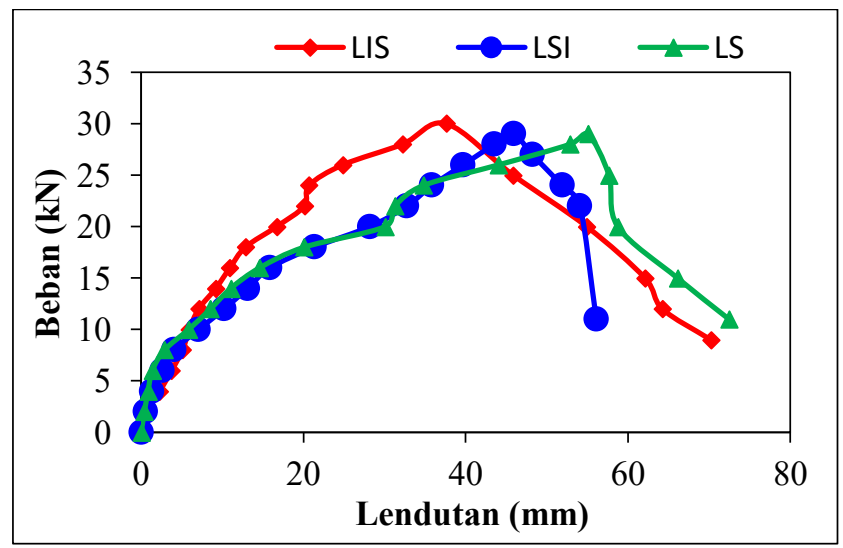

Gambar 4. Hubungan beban dan lendutan

Daerah pertama (I) adalah tahap sebelum terjadi retak (precracking) sampai terjadinya retak awal dan pada tahap ini sudah disertai rambatan debonding namun belum cukup besar. Seiring bertambahnya beban maka itu adalah tahap setelah terjadinya retak (post cracking) yang ditunjukkan pada daerah kedua (II) dan pada tahap ini rambatan debonding pada joint sudah terjadi namun perambatan debonding tidak dilanjutkan kedaerah balok dikarenakan pemasangan sabuk pada daerah balok yang dilanjutkan dengan daerah ketiga (III) yaitu tahap dimana lapisan GFRP-S masih mampu menahan beban (post serviceability cracking) sampai balok mengalami kegagalan dengan sobeknya lapisan dan ikatan diagonal GFRP-S pada tipe LS dan LSI dan sobeknya sabuk GFRP-S pada tipe LIS.

Pada Tabel 1 terlihat bahwa perbedaan lendutan antara beton pracetak tipe LS, tipe LSI dan tipe LIS pada saat beban maksimum cukup besar. Hal ini menunjukkan bahwa ikatan diagonal cukup berpengaruh terhadap kekakuan sambungan, dimana beton pracetak tipe LS memiliki lendutan yang cenderung lebih besar dibanding dengan beton pracetak lainnya. Pada beton pracetak tipe LIS memiliki lendutan yang cenderung lebih kecil walaupun menerima beban yang relatif sama. Hal ini disebabkan pada ikatan diagonal juga dipasangi sabuk, sedangkan untuk tipe LSI dipasangi ikatan diagonal setelah balok dipasangi sabuk yang menunjukkan bahwa metode pemasangan ikatan diagonal tipe LIS lebih efektif dikarenakan ikatan diagonal dimanfaatkan lebih maksimal untuk meningkatkan kekakuan pada sambungan.

Penambahan GFRP-S pada beton pracetak dengan beberapa variasi memberikan nilai momen maksimum yang relatif sama. semua tipe beton pracetak tidak memiliki momen maksimum yang cukup berbeda jauh. Hal ini berarti pengaruh penambahan ikatan diagonal tidak cukup nampak terhadap momen maksimum atau dalam hal ini peningkatan kapasitas beban. Hal ini disebabkan penambahan ikatan diagonal GFRP-S tidak memiliki luas permukaan yang sama besar dengan lapisan GFRP-S. Penambahan GFRP-S pada beton pracetak dengan beberapa variasi memberikan nilai lendutan pada saat beban maksimum yang berbeda. semua tipe beton pracetak memiliki lendutan maksimum yang cukup berbeda. Hal ini berarti pengaruh penambahan ikatan diagonal cukup berpengaruh pada kekakuan sambungan. Peningkatan kekakuan sambungan untuk beton pracetak tipe LSI terhadap tipe LS adalah $16,64 \%$ dan untuk tipe LIS terhadap tipe LS adalah $31,7 \%$ yang semuanya ditandai dengan lendutan yang terjadi pada saat beban maksimum semakin kecil. Hal ini disebabkan penambahan ikatan diagonal GFRP-S pada dua sisi joint balok - kolom sehingga meningkatkan kekakuan pada sambungan.

Model kegagalan yang terjadi pada penelitian ini yaitu rupture failure pada GFRP-S. Peningkatan beban secara terus menerus membuat komposit antara permukaan beton dengan GFRP-S berkurang sehingga GFRP-S terlepas dari beton. Namun dengan adanya penambahan sabuk pada balok maka dapat memperlambat rambatan debonding sehingga ketika tercapai beban maksimum terjadi sobekan pada lapisan GFRP-S. Pada model kegagalan tipe beton pracetak relatif sama namun untuk beton pracetak tipe LIS kerusakan GFRP-S terjadi pada sabuk GFRP-S sedangkan untuk tipe LS dan LSI kerusakan GFRP-S terjadi pada lapisan dan ikatan diagonal GFRP-S (Gambar 5, Gambar 6 dan Gambar 7). Hal ini disebabkan pada beton pracetak tipe LIS, sabuk GFRP-S mengikat lapisan dan ikatan diagonal GFRP-S secara bersama - sama tetapi beton pracetak tipe LIS ini efektif memanfaatkan kapasitas ikatan diagonal GFRP-S lebih maksimal dalam menerima beban sehingga dapat meningkatkan kekakuan sambungan.

Pada beton pracetak tipe LS menunjukkan model kegagalan beton yang terjadi adalah rusaknya GFRP-S (rupture failure of GFRP-S) seperti terlihat pada Gambar 5. Dengan adanya penambahan sabuk pada balok maka dapat memperlambat rambatan debonding sehingga ketika tercapai beban maksimum terjadi sobekan pada GFRP-S. Untuk beton pracetak tipe LSI menunjukkan model kegagalan beton yang terjadi adalah rusaknya GFRP-S (rupture failure of GFRP-S). Dengan adanya penambahan 
sabuk pada balok maka dapat memperlambat rambatan debonding sehingga ketika tercapai beban maksimum terjadi sobekan pada GFRP-S (Gambar 6). Sedangkan untuk beton pracetak tipe LIS menunjukkan model kegagalan beton yang terjadi adalah rusaknya GFRP-S (rupture failure of GFRP-S). Dengan adanya penambahan sabuk pada balok maka dapat memperlambat rambatan debonding sehingga ketika tercapai beban maksimum terjadi sobekan pada GFRP-S (Gambar 7).

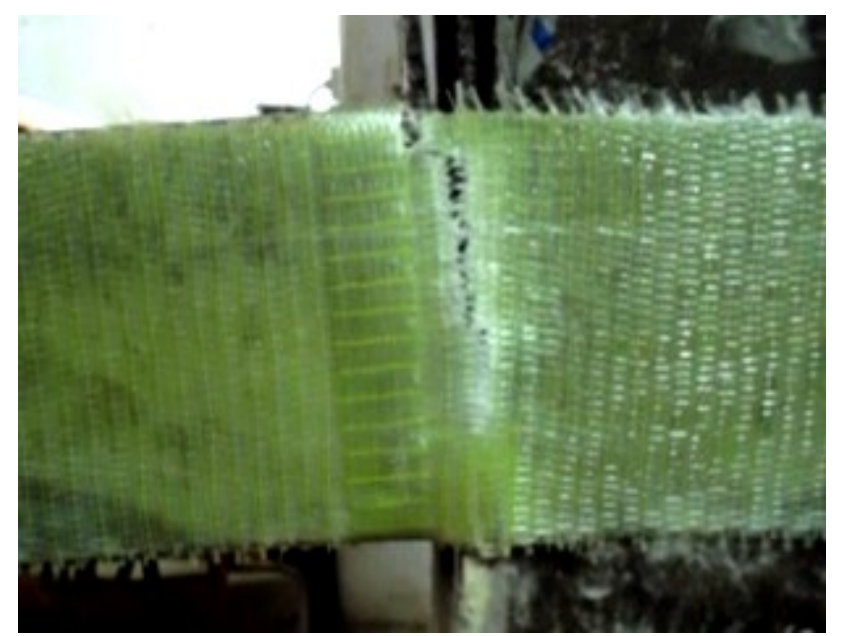

Gambar 5. Model keruntuhan beton pracetak Tipe LS

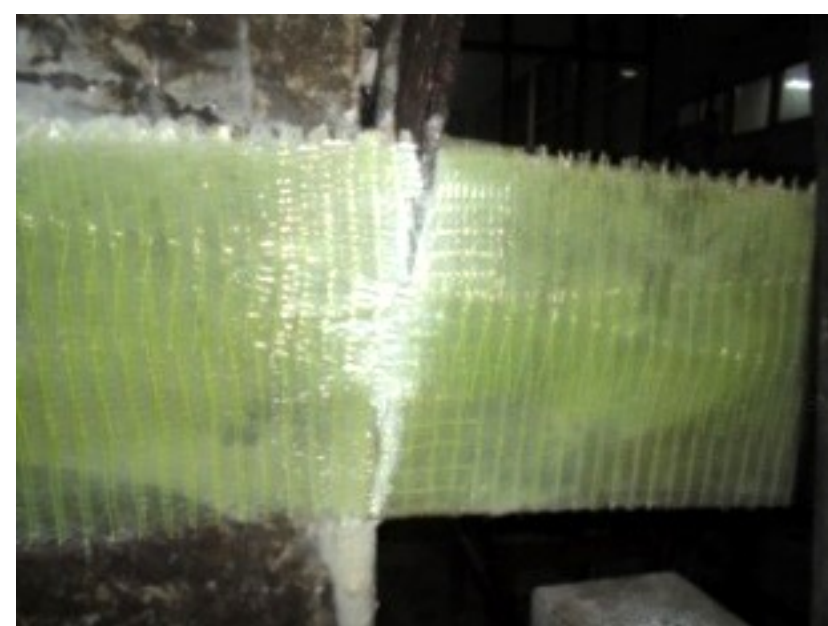

Gambar 6. Model keruntuhan beton pracetak Tipe LSI

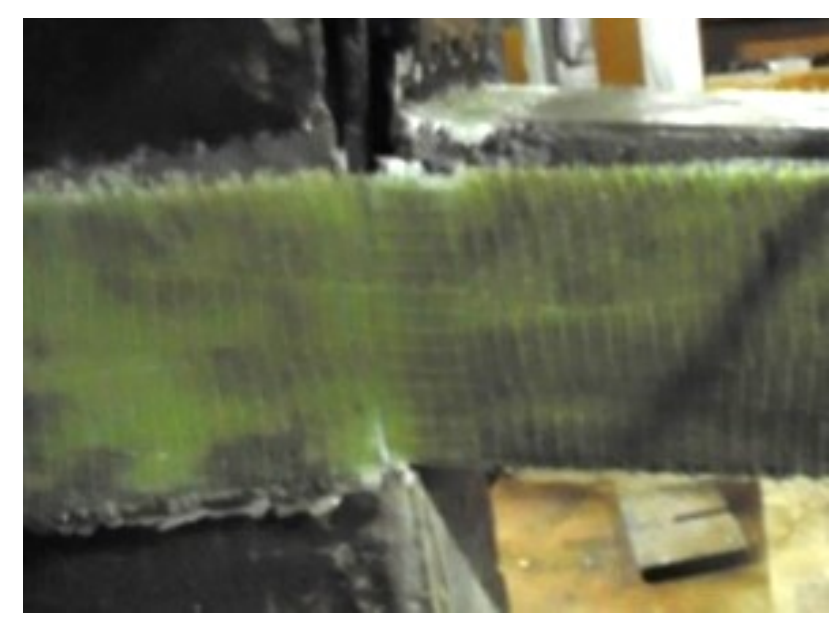

Gambar 7. Model keruntuhan beton pracetak Tipe LIS

\section{Kesimpulan}

Peningkatan kapasitas momen maksimum pada joint balok- kolom dengan penambahan ikatan diagonal GFRP-S sebesar 3,45\%. Peningkatan kekakuan sambungan pada joint

balok-kolom dengan penambahan ikatan diagonal GFRP-S sebesar 16,64\% sampai 31,7\%. Model kegagalan yang terjadi pada beton pracetak adalah rusaknya GFRP-S yang ditandai dengan sobekan pada lapisan GFRP-S (rupture failure of GFRP-S).

\section{Daftar Pustaka}

[1] B. Kiswono and E. Jayanto, "Studi Perbaikan Balok Beton Bertulang Menggunakan Glass Fibre Reinforced Polymer (GFRP) Untuk Meningkatkan Kekuatan Tarik Pada Bending Momen", Agregat, vol. 2, no. 2, p. 159, 2017.

[2] M.A. Sultan and R. Djamaluddin, "Daktalitas dan Kapasitas Lentur Balok Beton Bertulang Dengan Perkuatan GFRP-S", Prosiding Konferensi Nasional Teknik Sipil 12, p. MT-25, 2018.

[3] M. Isneini, F. Alami, and R. Surahman, "Studi Numerik Pada Balok Beton Bertulang dengan Perkuatan Hybrid Menggunakan Glass Fiber Reinforced Polymer (GFRP) dan Wiremesh", Rekayasa: Jurnal Ilmiah Fakultas Teknik Universitas Lampung (RJITS), vol. 24, no. 1, p. , 2020.

[4] M.A. Sultan and R. Djamaluddin "Model Hubungan Kapasitas Rekatan Balok Beton Bertulang yang Diperkuat GFRP-S terhadap Lama Perendaman Air Laut", Media Komunikasi Teknik Sipil, vol. 25, no. 1, p. 19, 2019.

[5] A. Tata, A.F. Raffel, and R. Djamaluddin, "Debonding Failure Pada Balok Beton Bertulang dengan Perkuatan Lembar GFRP Yang Dipengaruhi Beban Berulang dan Rendaman Air Laut", Jurnal Sipil Sains, vol. 8, no. 16, p. 1, 2018.

[6] ACI Committee 318, Building Code Requirrement for Structural Concreate (ACI-08) and Commentary, Farmington Hills USA: American Concreate Institute, 2008.

[7] ACI Committee 440.2R-08, Guide for the Design and Construction of Externally Bonded FRP Systems for Strengthening Concrete Structure, Farmington Hills USA: American Concreate Institute, 2008.

[8] I. Dipohusodo, Struktur Beton Bertulang, Jakarta: Gramedia Pustaka Utama, 1996.

[9] Hijriah, Studi Kekuatan Hubungan Balok-Kolom Pracetak dengan Sistem Glass Fiber Reinforced Polymer Sheet, Makassar: Universitas Hasanuddin, 2012.

[10] M.Y. Zacharia and G. Turuallo, "Analisis Struktur Baja Tahan Gempa dengan Sistem SRPMK (Struktur Rangka Pemikul Momen Khusus) Berdasarkan SNI 1729:2015 dan SNI", Rekonstruksi Tadulako: Civil 
Engineering Journal on Research and Development, vol. 1, no. 2, p. 9, 2020.

[11] E.G. Nawy, Beton Bertulang Suatu Pendekatan Dasar, Bandung: PT Refika Aditama, 1998.

[12] P.A. Costas, Analytical and Experimental Study of FRP-Strengthened RC Beam-Column Joints, Rio Achaia Greece: University of Patras, 2003.

[13] T. Paulay, M.J.N. Priestley, Seismic Design of Reinforced Concrete and Masonry Buildings, New Jersey: Wiley, 1992.

[14] S.R. Ravi and G.P. Arulraj, Experimental Investigation on Behavior of Reinforced Concrete Beam Column Joints Retrofitted with GFRP-AFRP Hybrid Wrapping, Coimbatore: Karunya University, 2010.

[15] SNI 03-2847-2002, Tata Cara Perhitungan Struktur Beton untuk Bangunan Gedung, Bandung: Standard Nasional Indonesia (SNI), 2002.

[16] Sunggono, Buku Teknik Sipil, Bandung: Nova, 1995.
[17] I. Umar, Studi Hubungan Kelenturan Balok pada Joint Balok-Kolom Pracetak dengan Sistem GFRP, Makassar: Universitas Hasanuddin, 2011.

[18] O.H. Abdel-Wahed, O.M. ElNesr, A.A. ElGhandour, W.A.S. Eldin, "Behavior of reinforced concrete beam-column joint with FRP", Proceeding of Eleventh International Colloquium on Structural and Geotechnical Engineering $11^{\text {th }}$ ICSGE, Egypt: Eo5RC38-1-15, 2005.

[19] P. Mindrasari, A. Awaludin, and Muslikh, "The Effect of Diameter and Anchorage Length of Keruing Wooden Dowels, Deformed Steel Dowels and GFRP Dowels on Pull-out Strength of Keruing Timber Block with Epoxy Resin Adhesive", Prosiding Civil Engineering and Environmental Symposium 2018 (CEES 2018), p. 01-1, 2018.

[20] J.B. Muda, B. Supriyadi, Muslikh, S. Siswosukarto, "Tinjauan Perilaku Dinamik Balok $\mathrm{T}$ dengan Perkuatan CFRP Jenis Wrap (Studi Eksperimental, Balok Beton Bertulang)", Dinamika Teknik Sipil, vol. 13 , no. 2, p. 60,2020 
This page is intentionally left blank 